\title{
La prohibición nacional del cannabis en México: revisión histórica de la relación entre leyes y ciencia
}

The national prohibition of cannabis in Mexico:

historical review of the relationship between law and science

José Domingo Schievenini Stefanon ${ }^{1}$

Fecha de recepción: 13 de octubre de 2020

Fecha de aceptación: 28 de enero de 2021 


\section{Resumen}

Este artículo documenta y analiza las leyes que en México habilitaron el espacio sobre el cual se construyó el paradigma prohibicionista en materia de drogas. Esa posición gubernamental de indole punitiva se consolidó durante el periodo comprendido entre 1917 y 1947, es decir, entre la promulgación de la Constitución Política y una serie de reformas realizadas al Código Penal Federal. La exploración y análisis de esas leyes requirió documentar la discusión científica en torno a los procesos legislativos: una discusión que en ciertos momentos respaldó, y en otros criticó, la posición gubernamental. En función de este trabajo de documentación histórica -y en el marco de las primeras prohibiciones nacionales e internacionales sobre el cannabis- se articulan opiniones médicas y jurídicas, y se exploran los puntos donde la ciencia y las leyes coincidieron, y aquellos donde se contrapusieron.

Palabras Clave: historia de las drogas, prohibicionismo, degeneración, políticas públicas, cannabis, marihuana.

\section{Abstract}

This article documents and analyzes the drug laws that enabled and created the space for the implementation of a prohibitionist paradigm in Mexico. An increasingly punitive government posture was adopted during the period from 1917 to 1947, i.e., between the promulgation of the Constitution and the incorporation of a series of reforms into the Federal Penal Code. The study and analysis of these laws required the documentation of scientific discussions surrounding the legislative process: discussions that sometimes supported and, at others, were critical of the government's position. Based on this review of the historical documentation-and within the framework of the initial domestic and international prohibitions of cannabis-medical and legal opinions are articulated, and the areas in which science and the law either coincided or entered into conflict are explored.

Keywords: history of drugs, prohibitionism, degeneration, public policy, cannabis, marijuana. 


\section{Introducción}

$\mathrm{E}$

n México, la aproximación gubernamental a las drogas (clasificadas por la Ley General de Salud como narcóticos, estupefacientes y psicotrópicos) se fundamenta en el artículo 73 de la Constitución Política, promulgada en 1917; en el Código Penal Federal, vigente desde 1931; y en la Ley General de Salud, que data de 1984, pero que en su genealogía remite a diversos códigos sanitarios, entre los que destaca el de 1926, por ser el primero en patologizar el uso de algunas drogas. En función de esas leyes, el Estado mexicano se ha sumado a un paradigma prohibicionista internacional que, si bien ha sido sostenido por más de un siglo (desde la Convención de La Haya en 1912), comenzó a mostrar signos de transformación en los últimos años. En México, el factor que originó el inicio de esa transformación fue la función jurisdiccional.

A partir de 2015, el Poder Judicial de la Federación resolvió una serie de juicios de amparo donde se discutió la libertad que los ciudadanos mexicanos tienen para consumir una droga prohibida en específico: la marihuana (cannabis índica y cannabis sativa, consideradas por la Ley General de Salud, ambas, como "narcóticos" de tipo "estupefaciente"; su principal componente psicoactivo, el tetrahidrocannabinol, es considerado por esta ley un "narcótico" de tipo "psicotrópico"). Tras la primera tesis aislada promulgada en 2015, este proceso jurisdiccional derivó en cinco resoluciones consecutivas resueltas por la Suprema Corte de Justicia de la Nación (SCJN) en un mismo sentido: la prohibición del uso adulto y personal de cannabis vulnera un derecho fundamental, el derecho al libre desarrollo de la personalidad. Este criterio dio pie a la creación de una jurisprudencia, la cual declaró inconstitucionales los artículos de la Ley General de Salud que avalaban la prohibición absoluta de la marihuana y sus derivados (SJCN, 2019). El señalamiento de inconstitucionalidad obligó al Poder Legislativo no sólo a modificar los artículos de la ley de salud, sino también a elaborar una "Ley Federal para la Regulación del Cannabis" (Senado de la República, 2020), para con ella garantizar la efectiva descriminalización de los usuarios de marihuana en México.

Paralelamente al trabajo jurisdiccional en materia de cannabis para uso personal y adulto (también llamado en los medios de comunicación lúdico o recreativo), durante la administración de Enrique Peña Nieto como titular del Poder Ejecutivo -2012-2018-, el tema del cannabis medicinal emergió en la agenda gubernamental. Considerando la regulación de la producción y venta de esta planta en Uruguay y en diversas entidades de Estados Unidos de América (EUA), se comenzó a dar voz a los distintos reclamos de sectores de la sociedad mexicana que requerían de productos derivados del cannabis con fines terapéuticos. En ese contexto, una propuesta de ley fue presentada a la Cámara de Diputados del Congreso de la Unión. Esta iniciativa fue aprobada en abril de 2017, con 374 votos a favor, 7 en contra y 11 abstenciones (Poder Ejecutivo Federal y Secretaría de Salud, 2017). Casi cuatro años después de haberse votado a favor, el 12 de enero de 2021, se publicó en el Diario Oficial de la Federación el "Reglamento de la Ley General de Salud en materia de control sanitario para la producción, investigación y uso medicinal de la cannabis y sus derivados farmacológicos" (Poder Ejecutivo, 2021). Con esta ley, además de reglamentar la regulación del cannabis medicinal a nivel nacional, se autorizó -e implicó la necesidad de impulsar- la investigación científica en general y clínica en particular en torno a esta planta (Poder Ejecutivo, 2021, artículos 3-XXII, 17, 24, 25 y 56). 
Si de acuerdo al Poder Legislativo, a la Secretaría de Salud y al Poder Ejecutivo (2017, 2021), la evidencia científica contemporánea muestra al cannabis como un producto cuya efectividad clínica para tratar múltiples padecimientos es superior a los medicamentos disponibles en el mercado; y si de acuerdo a la SCJN $(2016,2019)$ y al Senado de la República (2020), la evidencia científica muestra que los potenciales efectos negativos del uso recreativo no justifican su prohibición absoluta, entonces, ¿cuáles fueron las bases argumentativas y la evidencia científica sobre las que se fundamentó la prohibición de la marihuana en México? Para contestar esa pregunta es necesario mirar al pasado, específicamente al momento cuando, tras la promulgación de la Constitución Política de 1917, inició un proceso legal que determinó la posición del Estado mexicano con respecto a las drogas.

Durante el periodo de consolidación del prohibicionismo que se analizará en este artículo (19171947) no sólo se promulgaron las leyes que han sostenido por prácticamente un siglo el marco jurídico sobre drogas en México, sino que también se discutieron insumos científicos que respaldaron o criticaron la posición legislativa. Este artículo tiene como primer objetivo la documentación de esas leyes y de la evidencia científica que las circunscribía. En función de este trabajo de documentación histórica, el segundo objetivo radica en articular las voces que en el terreno médico y jurídico analizaron al cannabis en el marco de las primeras prohibiciones nacionales. Se precisarán los puntos donde la ciencia y las leyes coincidieron y aquellos donde se contrapusieron. Las posiciones afines y las antagónicas en torno a la marihuana se establecieron de una manera similar a como ocurre en la actualidad, desde considerarla una planta que daña a sus consumidores, señalados como enfermos y delincuentes, hasta clasificarla como un valioso medicamento. Para ello, en la primera sección de este artículo se ahonda en cómo la protección de la "raza" mexicana fue el eje de discusión detrás de la prohibición nacional del cannabis en el periodo de 1917 a 1926; en la segunda se analiza cómo, en el periodo de 1926 a 1931, las ideas degeneracionistas se entrelazaron discursivamente con una supuesta protección de la "salud" para justificar la prohibición de las drogas y la criminalización de sus usuarios; en la tercera, se desglosan varios artículos publicados en revistas especializadas de la época, entre ellos "El mito de la marihuana", publicado en la revista Criminalia en 1939, el cual es una fuente documental medular para el análisis histórico de la relación entre ciencia y drogas en México; y por último, en la sección final, se expone el tratamiento de la evidencia científica detrás de la prohibición en la década de 1940: una década en la cual se estableció una de las reformas penales más importantes para el proceso de consolidación del paradigma prohibicionista vigente en la actualidad.

La discusión detrás de las primeras prohibiciones de la marihuana en México es un tema poco explorado en la academia. Sobresalen los trabajos de Isaac Campos (2010, 2012), Ricardo Pérez Montfort (2016) y Domingo Schievenini $(2018,2021)$. La obra de Campos aborda la historia de la marihuana en una temporalidad que abarca la segunda mitad del siglo XIX y las primeras dos décadas del XX. El trabajo de Pérez Montfort, centrado en la historia cultural de México, abarca las drogas en general, por lo cual no hay una atención puntual al caso específico de la marihuana. La obra de Schievenini aborda la temporalidad 1912-1961, centrándose en los aspectos jurídicos detrás de la criminalización del cannabis. Este artículo se construye sobre las bases de esos tres trabajos, abarcando la temporalidad 1917-1947, es decir, una temporalidad posterior a la de Campos, que reduce y delimita la estudiada por Schievenini. Además, retomando los planteamientos de Pérez Montfort, este artículo se enfoca en el caso nacional, específicamente la relación entre leyes y evidencia científica, pero lo hace centrándose exclusivamente en 
el caso de la marihuana. En este sentido, también sobresalen estudios enfocados en el cannabis dentro de otras naciones, como los de Jerome Himmelstein (1983), Catherine Carstairs (2006), James Mills (2013), Emily Dufton (2017), Bradley Borougerdi (2018) y David Guba (2020), los cuales, desde miradas diversas, abordan la discusión científica y política en otras jurisdicciones: Mills en Gran Bretaña, Himmelstein y Dufton en EUA, Carstens en Canadá, y Guba en Francia. Borougerdi explora la historia de esta planta en el "mundo atlántico". Un denominador común en estas obras radica en señalar que, sin minimizar sus potenciales peligros, la desinformación en torno al cannabis ha sido un factor determinante en el debate legislativo. Este artículo busca sumarse a la pauta dictada por los trabajos mencionados, subsanando el vacío historiográfico que existe en el caso mexicano y abonando a la construcción de "La Nueva Historia de las Drogas en Latinoamérica” (Gootenberg y Campos, 2015). La relevancia de esta temática radica en la urgencia de aportar insumos científicos sólidos a la discusión en torno a las drogas que actualmente se desarrolla en la agenda pública mexicana: una discusión que, por su importancia en el terreno legislativo y en el eventual diseño de políticas públicas, obliga a abordar el tema con pensamiento crítico y rigor historiográfico.

\section{Degeneración de la raza, 1917-1926}

En las discusiones del Congreso Constituyente, celebradas a finales de 1916 y principios de 1917, la única intervención donde se mencionó la marihuana estuvo a cargo del diputado José María Rodríguez. En esa intervención afirmó que la "degeneración de la raza mexicana" era un hecho demostrado por la estadística y que, por lo tanto, "para corregir esta enfermedad de la raza provenida principalmente por sustancias medicinales como el opio, la morfina, el éter, la cocaína, la marihuana, etcétera” se necesitaban medidas enérgicas (Congreso Constituyente, 2016, pp. 136 y 137). Se requería de una respuesta gubernamental que contrarrestase el uso y comercio "de estas sustancias tan nocivas a la salud, que en la actualidad han ocasionado desastres de tal naturaleza, que han multiplicado la mortalidad al grado que ésta sea también de las mayores del mundo" (Congreso Constituyente, 2016, p. 137). En aquellas discusiones no se opuso excepción alguna al comentario sobre la marihuana emitido por el diputado Rodríguez.

En varias otras intervenciones dentro del Congreso Constituyente se mencionaron los peligros que corría la población y la "raza" mexicana de "degenerarse", pero en esas intervenciones no se aludió a la marihuana. Más bien se hizo referencia de manera enfática a las bebidas alcohólicas, principalmente al pulque. En función del problema de alcoholismo que vivía México en las primeras décadas del siglo XX, se discutía con ímpetu ideológico la posibilidad de la prohibición absoluta del alcohol embriagante (Piccato, 1992). Al final, estas preocupaciones dieron pie a que en el texto final de la Constitución de 1917, en la fracción 16 del artículo 73, se estableciera como facultad del Congreso de la Unión y del Consejo de Salubridad la implementación de una "Campaña contra el alcoholismo y contra la venta de sustancias que degeneran la raza”. En esa premisa ha descansado, desde 1917 y hasta la actualidad, el fundamento constitucional del combate gubernamental a las drogas, sus productores, sus traficantes, y sus usuarios.

Tres años después se promulgó la primera ley secundaria basada en la fracción 16 del artículo 73 constitucional. Se trató de las "Disposiciones sobre el comercio de productos que pueden ser utilizados para fomentar vicios que degeneren la raza y sobre el cultivo de plantas que pueden ser empleadas con el mis- 
mo fin" (Poder Ejecutivo Federal y Secretaría de Gobernación, 1920). Si bien fue un decreto promulgado por el titular del Poder Ejecutivo, el contenido de las disposiciones fue elaborado por el Departamento de Salubridad Pública. Con esta disposición se estableció la prohibición nacional de la marihuana en México, a manos de una institución sanitaria facultada para emitir sanciones económicas y administrativas, sin la necesidad aún de la intervención de la autoridad judicial. Destaca que en este decreto de 1920, cocaína, opio, morfina, y heroína seguían siendo considerados medicamentos y su importación era permitida, incluso por particulares, siempre y cuando se obtuviera el correspondiente permiso del Departamento de Salubridad, quien lo debía otorgar solamente "a establecimientos comerciantes de drogas que tengan un responsable farmacéutico legalmente titulado" (Poder Ejecutivo Federal y Secretaría de Gobernación, 1920, artículo 2). A través de estos permisos, el opio podría cultivarse en territorio mexicano: una permisión polémica dada la preocupación que este producto había levantado en el contexto internacional a partir de la Convención de La Haya de 1912, y dada la coerción ejercida por el gobierno de EUA para que México tomase medidas encaminadas a impedir su contrabando (Departamento del Tesoro, 1916). Sin embargo, con respecto a la marihuana, llama la atención que fue la única de las sustancias enlistadas en el decreto excluida como objeto de regulación medicinal. Independientemente de los fines con los que se consumiera, ya fuesen recreativos o medicinales, esta disposición de 1920 fue clara al respecto: "Queda estrictamente prohibido el cultivo y comercio de la marihuana" (Poder Ejecutivo Federal y Secretaría de Gobernación, 1920, artículo 5). Esta fracción resalta porque el uso médico de la planta y de varios de sus derivados, al igual que cocaína, opio, morfina, y heroína estaban permitidos por el Código de Salubridad de 1902, vigente en ese momento (Poder Ejecutivo Federal y Secretaría de Gobernación, 1903, artículos 201-217).

Por otro lado, destaca que en el título del decreto de 1920 aparecieron, al igual que en el artículo 73 de la Constitución de 1917, las ideas degeneracionistas como justificante de la prohibición ("productos que pueden ser utilizados para fomentar vicios que degeneren la raza”). Al hablar de degeneración racial, los legisladores mexicanos incorporaban en sus preocupaciones un discurso con aspiraciones científicas traído de Europa en las últimas décadas del siglo XIX: un discurso que no sólo hablaba de degeneración, sino que entremezclaba el pensamiento positivista con las preocupaciones eugenésicas sobre la herencia. Estas ideas fueron adoptadas por la élite científica en el Porfiriato (Ruíz, 1987; González, 1988; Suárez, 2005). La perspectiva degeneracionista se entrelazó discursivamente con la medicina científica, derivando en políticas orientadas a fortalecer y regenerar los componentes físicos y sociales de la población mexicana. Estas ideas se ajustaron a las necesidades higienistas y de disciplina social que buscaban las autoridades mexicanas durante la década correspondiente al periodo revolucionario (Knight, 1990; Campos, 2010), tal y como pudo observarse en el Congreso Constituyente, logrando una clara continuidad discursiva durante los gobiernos posrevolucionarios (Urías, 2005; Aréchiga, 2007).

En las primeras dos décadas del siglo XX, los esfuerzos antialcohólicos propios del siglo XIX englobaron dentro de sus preocupaciones el uso de nuevos intoxicantes: además de las bebidas embriagantes, opio y marihuana. El uso de ambos productos vegetales se insertó dentro de la categoría clínica de las toxicomanías. Sin embargo, cuando las élites médicas y políticas hablaban de "degeneración" hacían alusión a la necesidad de una campaña de prevención y de profilaxis social que atajase no sólo el alcoholismo y las toxicomanías, sino también mendicidad, prostitución, diversas enfermedades contagiosas, e insalubridad general. Se buscaba evitar la "degeneración" en cierta medida biológica pero mayormente social. Como 
parte de esas preocupaciones, el término "raza" no fue definido con claridad por el Estado mexicano, tampoco se precisó a qué se referían las autoridades con la "degeneración de la raza mexicana” (Rojas, 2016, p. 230; Schievenini, 2018, p. 349). En las discusiones del Congreso Constituyente, en el texto del artículo 73 de la Constitución de 1917, y en el decreto de 1920, las ideas degeneracionistas fueron empleadas de manera abstracta y se usaron en un sentido amplio, haciendo alusión a la regeneración de la población mexicana tras la catástrofe social ocurrida en la Revolución; una regeneración que debería ir de la mano del fortalecimiento de una sociedad que configuraba no sólo la nación, sino también la "raza" mexicana.

La prohibición nacional de la marihuana en México ocurrió cinco años antes de que el cannabis fuese contemplado en las convenciones internacionales, particularmente en la de Ginebra de 1925 (Sociedad de Naciones, 1925). Es decir, el gobierno mexicano no tenía una obligación vinculante para prohibir el cannabis en aquel año de 1920. Si bien se había firmado un tratado previo, en la Convención de La Haya llevada a cabo en 1912, y si bien aquel instrumento marcó el inicio de una tendencia prohibicionista a nivel global, en él solamente se contemplaba la regulación del opio.

Dentro de la oleada prohibicionista que a nivel global comenzaría a abarcar gradualmente nuevas drogas, el decreto que proscribió el cannabis en México no fue un caso atípico, sino parte de una tendencia perceptible a nivel regional. La prohibición de la marihuana ocurrió de manera prácticamente simultánea en varios estados de EUA y en varias provincias de Brasil, así como en las naciones de Cuba, Colombia, Panamá, Canadá, Jamaica, Trinidad y Tobago (y también en Sudáfrica e Italia), casos donde los argumentos racistas y clasistas, envueltos dentro de un ambiguo discurso degeneracionista, fueron determinantes para justificar la necesidad de las medidas prohibitivas (Schievenini, 2018, pp. 258-318). Al castigar a los usuarios de cannabis en esas naciones, los argumentos racistas y clasistas justificaron la criminalización de individuos pertenecientes a los sectores sociales donde se acostumbraba el uso de esta planta. Se trataba de los sectores pobres, desfavorecidos y marginados, es decir, los sectores que de acuerdo con la mirada de las élites científicas y legislativas, eran particularmente susceptibles a la degeneración (Stepan, 1991). Aquellas medidas prohibitivas en torno al cannabis, gestadas dentro de la lógica discursiva de cada nación, coincidían indirectamente con la pauta prohibicionista marcada por las convenciones internacionales y por el gobierno de EUA (Schievenini, 2018, pp. 578-606). En esos casos, la dinámica de interacción entre lo local y lo internacional en materia de drogas ejemplifica lo que Campos y Gootenberg (2015) han llamado "Transnacionalismo y escala”: una metodología para construir la Nueva Historia de las Drogas en Latinoamérica, documentando procesos regionales o nacionales determinados por variables tanto externas como internas.

\section{Delitos contra la salud, 1926-1931}

En consonancia con la pauta dictada por el artículo 73 constitucional, en 1926 se promulgó un nuevo Código Sanitario, el cual derogaba al de 1902, aquel que permitía los usos medicinales del cannabis. Este nuevo Código Sanitario reafirmaba lo expuesto por el decreto de 1920: la marihuana no era considerada por las leyes mexicanas un medicamento. A partir de este ordenamiento se consideraría al cannabis una "droga enervante", y a sus usuarios enfermos, "toxicómanos" que deberían ser internados en hospitales especiales para su tratamiento (Departamento de Salubridad Pública, 1926, artículos 198-212). Iniciaba 
entonces la patologización nacional de los usuarios de marihuana en México; una patologización que en el lustro posterior se transformaría en criminalización.

En México, los "delitos contra la salud" fueron tipificados a partir del Código Penal Federal de 1871. Dentro de esos delitos aún no se contemplaba el consumo de drogas, se establecía castigo, más bien, a quien adulterase bebidas, alimentos, y medicamentos (Ministerio de Justicia e Instrucción Pública y Congreso de la Unión, 1871, artículo 842), protegiendo con ello la calidad del producto y, por ende, tutelando la salud individual, la salud de terceros, y la salud pública. La criminalización del consumo de drogas controladas comenzó seis décadas después, cuando en 1929 se promulgó un nuevo Código Penal Federal, que sustituyó al de 1871.

A partir del Código Penal de 1929, la prohibición sanitaria de la marihuana mutaría en una criminalización de sus consumidores, la cual se caracterizó, ya no por una intervención administrativa de la autoridad, sino por delimitar en la letra de la ley las condiciones para el envío de individuos a prisión (en caso de no ser considerados por la autoridad como adictos o toxicómanos) o, en su defecto, a hospitales especiales (en caso de mostrar signos de adicción o toxicomanía) (Poder Ejecutivo Federal y Secretaría de Gobernación, 1929, artículos 507-525). En ambos casos, toxicómanos o no, la intención gubernamental buscaba abordar al consumidor de "drogas enervantes" o "substancias preparadas para un vicio y que degeneran la raza" (así les llamaba el Código de 1929, retomando el espíritu del artículo 73 constitucional, del decreto de 1920 y del Código Sanitario de 1926), ya no mediante la regulación (como ocurría con el Código Penal Federal de 1871), sino caracterizando al consumidor como enfermo o como delincuente. La libertad de los ciudadanos mexicanos, esa libertad que casi un siglo después la SCJN (2019) llamaría derecho al libre desarrollo de la personalidad, fue limitada en función de la protección del bien jurídico "salud".

El nuevo código penal de 1929 no fue bien recibido en el gremio jurídico y, por su contenido general, fue objeto de un sinnúmero de críticas. Se conformó entonces una comisión para su revisión y reescritura (Speckman, 2008, p. 598). En ese contexto, mientras se discutía el nuevo ordenamiento, a principios de 1931, el médico Gregorio Onetto Barenque envió a la comisión revisora del Código Penal vigente, el de 1929, un trabajo de su autoría, titulado "La marihuana ante la psiquiatría y el Código Penal". En este trabajo, el autor se sumó a las críticas al Código Penal Federal de 1929 y, además, dejó en claro que una de las modificaciones indispensables debía centrarse en la sección correspondiente a los "delitos contra la salud". Recomendaba el endurecimiento de las penas relativas a estos supuestos penales, particularmente aquellos que involucraran a la marihuana (Onetto, 1931, pp. 3-7). Retomando los argumentos degeneracionistas, presentes ya en la Constitución Política de 1917, en el decreto de 1920, y en el Código Sanitario de 1926, justificaba la necesidad de ese endurecimiento afirmando que la marihuana "es un enervante del espíritu que enloquece, degenera la raza y mata" (Onetto, 1931, p. 45); además enfatizaba que esta planta "envenena el espíritu [por lo cual] el tratamiento de los marihuanos, como el de todos los toxicómanos y alcohólicos, debe hacerse en frenocomios especiales" (Onetto, 1931, p. 45). Sobre su tráfico y su uso aseveraba que, "como ocurre con el de todos los enervantes del espíritu, constituyen un delito contra la salud” (Onetto, 1931, p. 46), y en consonancia con esa afirmación, sus recomendaciones a la comisión redactora del Código Penal de 1931 concluían señalando que "los delitos contra la salud deben equipararse al homicidio calificado" (Onetto, 1931, p. 47).

La opinión de Gregorio Onetto Barenque era respaldada por prácticamente la totalidad de los médicos de línea conservadora, por un gran número de funcionarios públicos y periodistas, y por la mayoría 
de los jueces de la Ciudad de México y de otros estados de la República (Pérez, 2016, p. 262). Además, los argumentos médicos y jurídicos con los que se justificaba la sanción del consumo de marihuana eran avalados por una lógica institucional específica: por un lado, desde 1920 la letra de la ley consideraba ese consumo como una conducta degenerativa y patológica, y por el otro, desde 1925, circunscrita a la Convención de Ginebra, esta prohibición se vinculaba con las pautas internacionales. Esos factores internos y externos habilitaron el espacio institucional para que especialistas mexicanos esgrimieran sus opiniones contra la marihuana, y para que el gobierno mexicano pudiera ejercer su poder punitivo con el objetivo de proteger a la nación de lo que los facultativos consideraban una amenaza social.

El 17 de septiembre de 1931 entró en vigor un nuevo Código Penal, derogando al anterior de 1929. En los dos años que tomó su elaboración, la nueva comisión trató de redactar un texto ecléctico, evitando los postulados positivistas que caracterizaron al de 1929. Se atendieron las tradiciones jurídicas mexicanas, las formalidades constitucionales, las pautas sociales de la criminalidad y las circunstancias socioeconómicas de la nación (Speckman, 2008, p. 602). Dentro del nuevo Código Penal de 1931, la sección correspondiente a los "delitos contra la salud" expuso de manera más puntual lo esbozado por el Código Penal de 1929 sobre el castigo que debía imponerse al usuario de cannabis (Poder Ejecutivo Federal y Secretaría de Gobernación, 1931a, artículos 193-199). Además, la firmeza jurídica de este nuevo código al abordar las drogas residió en su vínculo complementario con el Reglamento Federal de Toxicomanía (Poder Ejecutivo Federal, 1931b), disposición que no existía cuando se promulgó el Código Penal de 1929 y que establecía con mayor precisión en qué casos y en qué circunstancias las autoridades debían considerar al usuario de drogas un enfermo que requería ayuda terapéutica y los casos y circunstancias donde debían calificarlo como un delincuente.

Sobre el consumo de marihuana como un potencial acto delincuencial, el Código Penal Federal de 1931 precisó las sanciones a aplicar (de uno a cinco años de prisión), replanteó cuáles serían consideradas "drogas enervantes" (reafirmando a la marihuana), y también amplió el catálogo de tipos penales que conformaban los "delitos contra la salud". Como parte de estas precisiones, se establecía sanción penal a quien "comercie, elabore, posea, compre, enajene, ministre gratuitamente y en general, verifique cualquier acto de adquisición, suministro o tráfico de drogas enervantes ... o con substancias preparadas para un vicio de los que envenenan al individuo y degeneran la raza" (Poder Ejecutivo Federal, 1931a, artículo 194). Destaca que en ese Código de 1931—al igual que en el Código Penal de 1929— se siguiera hablando de sustancias que "degeneran la raza". Los argumentos degeneracionistas con los que se prohibió la marihuana en el periodo de 1917 a 1926 no habían desaparecido. A pesar de haberse establecido la figura de los "delitos contra la salud", una categoría que parecía apelar a una lógica clínica y científica (que protegiera explícitamente la "salud"), las reminiscencias decimonónicas del discurso degeneracionista subyacían bajo la argumentación legislativa. Estas evocaciones discursivas que advertían sobre la degeneración de la raza se pueden observar tanto en la letra de la ley como en varios otros documentos como, por ejemplo, en el anteriormente citado escrito dirigido a la comisión redactora del Código Penal de 1931, a cargo del médico Gregorio Onetto, quien señalaba que "casi la totalidad de los toxicómanos son absolutamente incurables en el seno de la sociedad y la idea de readaptarlos a la misma es por completo imposible" (Onetto, 1931, p. 42). En ese sentido, Onetto afirmaba tajantemente que, ante la incapacidad de recuperación, la solución "no puede ser otra que la de apartar radical y definitivamente de la sociedad a los toxicómanos considerados como incurables, y para conseguir este resultado no hay más que de dos 
medios: la muerte y la reclusión perpetua" (Onetto, 1931, p. 42).

En este sentido, y con la intención de documentar la vigencia de los argumentos degeneracionistas detrás de la prohibición de las drogas, se hizo una revisión detallada de la revista Eugenesia, la cual fue creada y orquestada por la Sociedad Eugénica Mexicana. El título original de la revista fue Sociedad Eugénica Mexicana "Para el mejoramiento de la raza". Sin embargo, a partir del ejemplar publicado en diciembre de 1932 su nombre cambió a Eugenesia. Higiene y cultura física. Órgano de la Sociedad Eugénica Mexicana. Se revisaron cada uno de los ejemplares publicados entre la década de 1930 y la de 1960. Los resultados de esta revisión muestran que fueron pocos los artículos que tocan el tema de drogas en general, y que en ninguno se mencionó la marihuana en particular. Esta ausencia de publicaciones sobre el cannabis reafirma que la idea de la degeneración racial (en un sentido eugenésico y estrictamente biológico) no fue una razón directa detrás de la prohibición de esta planta en México: al igual que en el título del decreto de 1920 (que la consideraba una planta que "degeneraba la raza"), las ideas degeneracionistas no se usaban en un sentido literal, sino como un aliciente profiláctico para la supuesta protección y fortalecimiento de la población, la sociedad y la nación.

En la revisión de la revista Eugenesia se localizaron tan solo tres comentarios aislados relacionados con drogas. El primero de ellos se encontró en un número publicado a principios de 1932, en el cual la Sociedad Eugénica Mexicana emitió lo que ellos consideraban un "Decálogo Eugénico". Los puntos que lo constituían precisaban la necesidad de una vida donde imperara el amor y el honor, el dominio de los instintos sexuales, el alma optimista, la paternidad responsable, el cuidado de los enfermos en hospitales y no en el hogar, la vida como comedia y no como tragedia, el matrimonio exento de peleas para el bienestar de los hijos, y evitar las drogas y el alcohol. En el postulado específico referente a las sustancias intoxicantes, se podía leer "Drogas y alcohol dan el hijo peor" (Sociedad Eugénica Mexicana, 1932a, p. 20). Este punto del "Decálogo Eugénico" da cuenta de uno de los escasos registros documentales donde la revista Eugenesia se pronunció sobre el tema de las drogas, englobándolo en una serie de preocupaciones relativas al bienestar familiar. En este sentido, se encontraron un par de registros más: en el segundo, también de 1932, se describía a los "alcohólicos y toxicómanos" como una "digénesis biológica" (Sociedad Eugénica Mexicana, 1932b, p. 17). En el tercer registro, relativo al último número de la revista publicado en 1932, se mencionan varias ponencias presentadas dentro del Congreso Nacional Penitenciario. De entre esas ponencias hay algunas relacionadas con drogas: en primer lugar "La toxicomanía dentro de las prisiones", trabajo de Benjamín Arguello; en segundo lugar, "La acción del Departamento de Salubridad Pública en el tratamiento de los toxicómanos", presentado por Everardo Landa; en tercer lugar "La intoxicación por marihuana", un trabajo de Alfonso Millán y, por último, el "Tratamiento de los toxicómanos en la penitenciaria”, por parte de Juan Peón del Valle (Sociedad Eugénica Mexicana, 1932c, p. 39). Al margen de los trabajos presentados en el Congreso Nacional Penitenciario, cuyos títulos solamente fueron nombrados por la revista Eugenesia, sin que se comentase algo sobre su contenido, no se localizó comentario alguno relacionado con drogas hasta el año de 1940, cuando la revista de la Sociedad Eugénica Mexicana publicó el artículo "Los narcómanos" (Saavedra, 1940, p. 22). Tras este texto, el siguiente aparece una década más tarde, en 1950, cuando en una editorial de la revista se advierte sobre el peligro del tráfico de "narcóticos" (Sociedad Eugénica Mexicana, 1950, p. 47). En ambos textos — de 1940 y 1950 - se respalda la posición gubernamental que afirma la condición patológica de los toxicómanos, pero como ocurría en las publicaciones de la década de 1930, nada se menciona sobre las consecuencias 
biológicas, raciales y eugenésicas resultado del consumo de drogas.

La revisión de los ejemplares de la revista Eugenesia publicados durante las décadas de 1930, 1940 y 1950 arrojó como resultado que las temáticas recurrentes en el terreno del degeneracionismo y la eugenesia fueron, más que el uso de drogas, las siguientes: las leyes de la herencia, la importancia del cuidado de la infancia, higienismo, cultura física, educación sexual, matrimonio, esterilización, control de natalidad, y la repercusión y relevancia social de las políticas eugenésicas. Además de esas temáticas, las preocupaciones recurrentes eran alcoholismo, epilepsia, tuberculosis, prostitución, sífilis, y enfermedades venéreas. Esta revista fue la plataforma de divulgación científica del pensamiento eugenésico y degeneracionista en México; el hecho de que en ella no se publicasen notas sobre la marihuana evidencia que, efectivamente, la "degeneración de la raza" detrás de la prohibición era un argumento persuasivo, el cual apuntaba a la protección de una sociedad de tipo excluyente en vías de reconstrucción. Esto permite afirmar que la inclusión del argumento degeneracionista en la tipificación de los "delitos contra la salud" dentro de los códigos penales de 1929 y 1931 carecía de un aval científico sólido; lo cual evidencia que, al castigar el uso de cannabis, el Estado mexicano protegía una concepción imprecisa de la "salud" (Schievenini, 2018, pp. 578-606). Al criminalizar consumidores de marihuana, acusados de dañar o afectar lo que la letra de la ley nombraba "salud", el Estado mexicano ejercía su poder punitivo sin delimitar con claridad el bien jurídico que estaba tutelando: en el debate científico y legislativo no quedó claro si se trataba de la salud física o psicológica del usuario, la salud de terceros potencialmente perjudicables, la salud pública, la salud moral de la población o, en una continuidad discursiva desde la Constitución de 1917 , la salud de la raza mexicana.

\section{La revista Criminalia y "El mito de la marihuana", 1937-1940}

Tras la criminalización de iure del uso de cannabis en México, consolidada con el Código Penal de 1931, donde sí aparecieron artículos relativos al tema de la marihuana fue en la revista de ciencias penales Criminalia: una publicación orquestada desde sus inicios, en el año de 1933, por varios miembros de la Academia Nacional de Ciencias Penales y de la comisión redactora del Código Penal Federal de 1931 (Rojas, 2016, pp. 98, 112-113). El primer artículo relacionado con el cannabis publicado por esta revista apareció en 1939 y se tituló "Marihuana, el nuevo vicio", escrito por el doctor N. S. Yawger, quien se desempeñaba como perito psiquiatra en las cortes penales de EUA. Este artículo fue una traducción del publicado originalmente en idioma inglés, en el American Journal of the Medical Sciences, en marzo de 1938; su título original fue "Marijuana. Our New Addiction" (Yawger, 1938, pp. 351-360). En él se concluye que el uso de marihuana no es tan frecuente como el del opio o la cocaína, y que su consumo no tiene síntomas secundarios ni se conocen casos fatales; sin embargo, "usada en grandes cantidades, su acción obra directamente sobre el cerebro y produce con frecuencia trastornos mentales crónicos" (Yawger, 1939, p. 272). Al advertir sobre las posibles patologías mentales, este artículo comenzaba a aportar elementos clínicos sobre cuál podía ser la "salud" que se estaba protegiendo en el Código Penal Federal de 1931.

Un artículo posterior, también del año 1939, se tituló simplemente "Marihuana", escrito por los doctores Raúl Esquivel y Miguel González. En él se trató de "bosquejar algunos datos acerca de la historia y 
clasificación de esta interesante planta" (Esquivel y González, 1939, p. 370). Por su acción estupefaciente, afirmaban los autores, la marihuana "ha tenido numerosos adeptos en nuestro medio y ha causado graves actos delictuosos ... su uso se encuentra extendido entre soldados, presidiarios, ladrones y gente depravada" (Esquivel y González, 1939, p. 370). En el artículo no se menciona el tema de la degeneración, pero sí la depravación; una depravación que aumenta "la sed de sangre", explicando con ello "los frecuentes asesinatos espeluznantes a que da motivo. Las alucinaciones visuales que produce hacen que los intoxicados se defiendan de supuestos enemigos, volviéndose agresivos" (Esquivel y González, 1939, p. 377). Al igual que el artículo de Yawger, publicado en Criminalia meses atrás, se estableció un vínculo entre el consumo de la planta y los trastornos mentales.

Otro artículo que apareció en la revista Criminalia se tituló "Nuevas contribuciones al estudio de la cannabis", escrito por Jules Bouquet, experto farmacéutico de la Subcomisión de la Cannabis en la Sociedad de Naciones y amigo cercano de Harry Anslinger, considerado el "primer zar antidrogas" en el mundo, tras ser la cabeza del Federal Bureau of Narcotics en EUA, cargo que ocupó de 1930 a 1962 (Davenport-Hines, 2005, p. 331). El artículo era una traducción del original, en idioma francés, "Contributions à létude de la Cannabis" (Bouquet, 1937, pp. 27-42). En la versión en español de este artículo puede leerse que "tras los esfuerzos de la Sociedad de Naciones para intensificar la lucha contra el abuso de los estupefactivos [sic], el estudio del cáñamo índico ha recobrado su actualidad desde hace algunos meses" (Bouquet, 1939, p. 469). Bouquet argumentaba que no existía un consenso con respecto al valor terapéutico del cannabis y que, por el contrario, bajo los efectos de la marihuana el individuo sufre una intoxicación potencialmente peligrosa: pasa por una sensación de bienestar, risas espasmódicas, poderío y beatitud, con ciertas alucinaciones cenestésicas, como una falsa percepción de calor o frío, de alargamiento en los miembros, o una abierta confusión en la apreciación del tiempo; para después entrar en un periodo de clara confusión mental caracterizada por "desenfreno imaginativo [y por] visiones coloreadas [que] se orientan en el sentido de las tendencias subconscientes del consumidor" (Bouquet, 1939, p. 473). En aquel artículo, se señala también que al desaparecer la intoxicación tan solo queda depresión y que, además, el consumidor de marihuana pierde sus aptitudes sexuales y aumentan los trastornos mentales por "irritabilidad patológica"; sin embargo, se especifica que todos los fenómenos de perturbación mental desaparecen a los pocos días tras la privación del consumo de la planta (Bouquet, 1939, pp. 474-479).

A finales de la década de 1930, las opiniones médico-legales respaldaban las preocupaciones derivadas de las propiedades perjudiciales de la marihuana, avalando la percepción patológica y delictiva que del consumidor se tenía en las leyes. Sin embargo, la evidencia científica en torno al cannabis podría calificarse como escasa. En ese contexto, resaltan las contribuciones del médico Leopoldo Salazar Viniegra, quien se erige como un personaje crucial en la historia de las drogas en México. Nacido en el estado mexicano de Durango en los últimos años del siglo XIX, Salazar Viniegra estudió medicina en la Universidad Nacional, para después especializarse en psiquiatría en Francia y España. Fue director del Hospital Federal de Toxicómanos y del Hospital Psiquiátrico La Castañeda. Como representante del gobierno mexicano participó en distintas convenciones internacionales en materia de salud (Sociedad de Naciones, 1936). Con base en su experiencia en el terreno sanitario, Salazar Viniegra llegó a varias conclusiones que discrepaban de la lógica gubernamental durante la gestación y proceso de consolidación del paradigma prohibicionista en México. De entre los estudios que realizó resalta el titulado "El 
mito de la marihuana”, el cual originalmente había sido leído ante la Academia Nacional de Medicina en octubre de 1937, para eventualmente ser publicado en 1939 por la revista Criminalia.

"El mito de la marihuana" inicia con la narración de una serie de antecedentes donde el autor expone sus catorce años de experiencia en el Hospital Psiquiátrico La Castañeda, y donde también criticaba la falsedad de los trabajos sobre esta planta en México; después enumera esas supuestas falsedades en una sección titulada "Lo que se le atribuye a la marihuana", donde explica cómo durante su "práctica manicomial" se percató de la popularidad de la planta entre las clases pobres, "que son la clientela habitual de ese sanatorio" (Salazar, 1939, p. 206). Pero matiza que, a pesar de su extensa popularidad, entre los consumidores no encontró un solo caso "en el que con toda seguridad se pudiera atribuir la psicosis al uso de la marihuana" (Salazar, 1939, p. 206). De igual forma señaló que en todos aquellos pacientes a quienes sus familiares o médicos consideraban afectados mentalmente por el consumo de esta planta, "una observación cuidadosa logró, en todos los casos, identificar algún padecimiento preexistente" (Salazar, 1939, p. 206).

La primera parte sustancial del texto se aboca a desmentir los ya mencionados trabajos tanto de Onetto Barenque, como de Jules Bouquet y N.S. Yawnger (Salazar, 1939, pp. 207-214). Refiriéndose a la múltiple variedad de argumentos contra la marihuana en la primera mitad del siglo XX, Salazar Viniegra puntualizó que estas opiniones contenían inexactitudes y errores, y tan sólo algunas nociones verídicas, lo cual él atribuía "a que sus autores, alcanzados de una curiosa sugestión colectiva, pasan por alto determinados hechos y aceptan otros con crítica notoriamente insuficiente que muchas veces son de ostensible falsedad" (Salazar, 1939, p. 217). Tras esta afirmación desarrolla una sección titulada "Lo que produce y lo que no produce la marihuana”, para la cual se basó no sólo en la observación de los pacientes del hospital, sino también en el consumo personal que hizo de la planta, y en experimentos donde suministró marihuana a diversos individuos. "Todas estas pruebas — escribió Salazar Viniegra - se han realizado en el Hospital de Toxicómanos, habiendo procurado que se cumpliesen condiciones análogas a las que presiden las sesiones de nuestros folclóricos marihuanos" (Salazar, 1939, p. 215). Las conclusiones que presenta en ese punto son meticulosas en términos técnicos, enfocadas a los mecanismos de acción del cannabis en el funcionamiento pulmonar y en el sistema nervioso central, puntualizando su inocuidad general. Menciona que estas conclusiones eran respaldadas por estudios llevados a cabo en el Instituto de Psicopedagogía, en particular por el doctor Jorge Segura Millán (Salazar, 1939, pp. 215-227).

Con respecto a la siguiente sección, titulada "Sobre los pretendidos efectos de la marihuana en los trastornos mentales y la delincuencia”, afirmaba que se trataba de uno de los capítulos más importantes del artículo porque contradecía "la gran cantidad de absurdos y falsedades que a este propósito se han acumulado y por las graves consecuencias que tiene para la aplicación del Código Penal" (Salazar, 1939, p. 227). Con respecto a los crímenes realizados bajo el influjo de la "intoxicación marihuanica", Salazar Viniegra criticaba que constantemente en la prensa aparecían relatos "truculentos" atribuyendo a los usuarios de marihuana toda clase de características violentas (Salazar, 1939, p. 232). Ese tema (la relación entre cannabis y locura y violencia) fue documentado por el historiador Isaac Campos (2012), quien realizó un estudio cuantitativo sobre la prensa mexicana, enfocándose en una temporalidad previa, la cual iniciaba en la década de 1850 y finalizaba con la prohibición nacional del cannabis en 1920. Campos llegó a una conclusión similar: prácticamente la totalidad de las notas de prensa relativas a la marihuana asociaban a esta planta con la locura y con la violencia de tipo maniático, sin que existiese un referente 
documental que avalase esa relación más allá del sensacionalismo editorial (Campos, 2012, pp. 80-152). A este respecto, Salazar Viniegra precisa que "Mientras los trastornos mentales por influencia del alcohol constituyen el porcentaje máximo de aislados en el manicomio de Mixcoac, los determinados por marihuana sólo existen en las crónicas periodísticas que con obstinada reverencia los relatan" (Salazar, 1939, p. 237). Tras esa afirmación, comenta que si se comparase con la problemática del alcoholismo, la cuestión del uso de marihuana en México "no merece la importancia de problema social ni humano: el estudio científico de ella presenta, en cambio, siempre interés para quien, libre de prejuicios, la someta a sus disciplinas" (Salazar, 1939, p. 237).

Sobre el perfil del consumidor de marihuana, en este texto se señala que "nuestro pueblo bajo tiene que cargar su felicidad a cuenta de la fantasía, cuando la realidad se la niega. Y se la niega casi siempre" (Salazar, 1939, p. 237). Esta es la razón por la que Salazar Viniegra afirmaba que esta planta "ha quedado monopolizada por los ignorantes y los pobres; muchos jóvenes ociosos, de constitución toxicómana, la toman también y la aprovechan para satisfacción de sus tendencias, como tomarían alcohol o la morfina" (Salazar, 1939, p. 237). A este respecto, sugería modificar el criterio punitivo que ha regido al Código Sanitario y al Código Penal, "que tan exaltada como injustificadamente persiguen y condenan el uso de la marihuana" (Salazar, 1939, p. 237). Precisó que de acuerdo con las estadísticas del Departamento de Salubridad, más del ochenta por ciento de sentencias por "delitos contra la salud" se debían a posesión, uso y tráfico de marihuana, "muy frecuentemente por una simple colilla que se encuentra a un desventurado, se le somete a juicio y se le condena a 6, 12 y más meses de prisión" (Salazar, 1939, p. 237). En esta última cita se puede observar cómo el problema que se vive hoy en día en México -el de una población penitenciaria repleta de individuos detenidos por posesión de marihuana (Pérez, 2016) - existía ya en la década de 1930. Pero esto no parecía importar a los detractores del consumo de esta planta y a quienes apoyaban su criminalización en aquella época: como lo muestra Salazar Viniegra, las opiniones que abordaban las características dañinas de la marihuana eran superiores en número a las que tenían un enfoque distinto. Además, esas opiniones contrarias al cannabis eran mejor asimiladas por las autoridades legislativas y judiciales, y eran legitimadas por las convenciones internacionales.

Quien respaldó públicamente las ideas expuestas por el doctor Salazar Viniegra fue el médico Jorge Segura Millán. Como se señaló anteriormente, Segura realizó estudios afines a los de Salazar dentro del Instituto de Psicopedagogía. Con base en estas investigaciones, incluso escribió un trabajo al respecto, titulado "Marihuana, estudio médico y social", publicado en 1939, donde elaboró con diligencia y detalle los argumentos esbozados por Salazar Viniegra. El trabajo del doctor Jorge Segura interrelaciona una notable variedad de temas: profundiza en la historia y en la clasificación botánica y química de la planta; hace alusión a los experimentos realizados en humanos y animales, particularmente en perros; precisa las aplicaciones medicinales del cannabis; también explora sus peligros psicopatológicos, afirmando, en una clara continuidad con lo planteado por Salazar Viniegra, que su relación con las enfermedades mentales existe, pero es excepcional y está determinada neurológicamente por una predisposición hereditaria. Menciona también la popularidad de la marihuana en el ejército nacional; de igual forma, repara en el problema del tráfico ilegal de drogas, y analiza la propaganda periodística, culpando a los diarios mexicanos por haber desarrollado un claro sensacionalismo en torno a la planta, y también por haber entrelazado su simple consumo con la imagen negativa de los traficantes. En términos generales, elabora un argumento sobre los nulos efectos perjudiciales 
que, desde su opinión y sus observaciones, el consumo de marihuana ha provocado en la sociedad mexicana (Segura, 1939, pp. 7-190).

Segura Millán afirmó que el desprecio por la marihuana desaparecería en las próximas décadas, cuando el acercamiento científico al tema ofreciese "amplios y hermosos espacios para la experimentación, dejando atrás la mirada de horror con la que las generaciones anteriores de la sociedad mexicana han visto a esta planta" (Segura, 1939, p. 189). Sobre el trabajo y las opiniones de Jorge Segura Millán se realizaron reseñas positivas en la prensa, donde se le consideró "el primer esfuerzo coordinado para restituir el problema de la mariguana al campo de la ciencia" (El Universal, 1939, p. 17; El Nacional, 1939, p. 9). El Departamento de Estado del gobierno de EUA incluso estaba enterado de este trabajo: guardaba un resumen en inglés dentro de la misma carpeta donde archivaba información relativa a Salazar Viniegra. En esa carpeta también fue posible encontrar otras notas donde se descalificaban los trabajos de ambos, y donde se les adjetivaba como "soñadores" y "poco científicos" (Departamento de Estado, 1942).

Al margen de los estudios que se hacían en el Instituto de Psicopedagogía, Leopoldo Salazar Viniegra había publicado, en 1938, otro texto en la revista Criminalia, titulado "Exposición de motivos para un nuevo Reglamento de Toxicomanías", donde radicalizaba la posición de descriminalizar a los usuarios de drogas, recomendando al Estado mexicano monopolizar la producción y distribución de estos productos, para así atacar al narcotráfico. Tras ese artículo, el doctor Salazar Viniegra fue entrevistado por Carmen Báez, para el diario El Nacional. En el inicio de esta entrevista se le presentaba "como el hombre que tiene en sus manos la solución del problema de la toxicomanía en México" (El Nacional, 1938, p. 5). En esta entrevista, el doctor Salazar Viniegra atribuye la existencia de los problemas de toxicomanía y narcotráfico a la "torpeza legislativa" (El Nacional, 1938, p. 5). Las ideas de Salazar Viniegra fueron un vector influyente en el intento de transformación en las políticas de drogas en la fase final del sexenio Cardenista (Smith, 2019), por lo cual fueron motivo de opinión dentro de los gobiernos mexicano y estadounidense, así como entre las élites médicas y políticas de la sociedad mexicana.

Poco después de la entrevista realizada por Carmen Báez, en la prensa aparecieron varias notas relacionadas con lo planteado por el doctor Salazar. Por ejemplo, una columna publicada por El Nacional, titulada simplemente "Marihuana". En ella se aplauden las ideas de Salazar Viniegra, e incluso se puede leer que "la intoxicación marihuánica no produce ninguno de los síntomas mentales que se le atribuyen. La conducta del marihuano no entraña problemas graves ni para la familia ni para la sociedad" (Elizarras, 1939, p. 14). Otra columna, publicada en El Universal, se contraponía a esa opinión; se titulaba "La Mariguana sí es tóxica”, en ella, contradiciendo a Salazar Viniegra, se narraba una serie de anécdotas que mostraban cómo el consumo de esta planta provocaba episodios de conducta desequilibrada (Urquijo, 1939, p. 3).

Ante la confrontación de posiciones, el diario La Prensa recabó la opinión de cuatro lectores habituales de esa publicación. Algunas opiniones señalaban que la tesis del doctor Salazar Viniegra era justificada, "pero inaplicable porque con ello se da margen al desarrollo del consumo de enervantes" ( $\mathrm{La}$ Prensa, 1939, p. 20). Otra opinión, atribuida al señor Emeterio Arreola, precisaba sí estar de acuerdo con Salazar Viniegra, particularmente en "expedir permisos para que viciosos desahuciados se provean de cantidades mínimas de las drogas para sus necesidades en calidad de enfermos" (La Prensa, 1939, p. 20). En sentido contrario, otro lector, de nombre Antonio Gutiérrez opinó que "el doctor Salazar Viniegra se está convirtiendo en un propagandista del consumo de las drogas heroicas, pues debe de recordarse 
el asunto de la marihuana, de la cual dijo dicho facultativo que carecía de elementos nocivos, lo cual es una absoluta falsedad" (La Prensa, 1939, p. 20). Por otro lado, el abogado Altogo Naroba precisó que él estaba completamente de acuerdo con la tesis del doctor Salazar Viniegra: "es natural que los individuos que han sido declarados incurables en el consumo de estupefacientes reciban el auxilio de las autoridades para no caer en las garras de los traficantes que extorsionan y exploran inhumanamente a los viciosos" (La Prensa, 1939, p. 20). Este abogado incluso afirmaba que a través del Departamento de Salubridad los usuarios de drogas, los toxicómanos, tenían una ligera esperanza de recuperación. El último entrevistado fue el señor Ignacio Enríquez, quien, recuperando indirectamente la lógica degeneracionista, opinó: "es preferible que se abandone a su suerte a los pocos viciosos que tienen permisos legales para proveerse de drogas heroicas, que seguírseles proporcionando por medio de maniobras que no parecen ni muy legales, ni muy cuerdas" (La Prensa, 1939, p. 20).

En el sentido de las opiniones en la prensa, otro ejemplo de las reacciones a los postulados de Salazar Viniegra son aquellas emitidas por el médico Gregorio Onetto Barenque, quien como se señaló previamente, en 1931 había recomendado a la comisión redactora del Código Penal que criminalizara a los usuarios de cannabis debido a que estos "degeneraban la raza”. En 1938 Onetto reapareció al presentar un nuevo trabajo, titulado "La Mariguana ante la Academia Nacional de Medicina. Refutación al trabajo presentado por el doctor Leopoldo Salazar y Viniegra”. En este texto exhibió las mismas conclusiones que el anterior de 1931, es decir, afirmó que la marihuana es una "ponzoña" que "envenena el espíritu, degenera la raza y mata" y que "los delitos contra la salud deben equipararse con el homicidio calificado" (Onetto, 1931, pp. 45 y 46), pero en esta ocasión, como lo indica el título de su trabajo, utilizó sus planteamientos para refutar puntualmente a Salazar Viniegra. Onetto Barenque señaló que la razón por la que escribió su refutación fue la favorable aceptación del trabajo de Salazar dentro del gremio académico, médico y psiquiátrico, por lo cual "era necesario aclarar una situación por demás compleja e inequívoca, el hecho innegable de que la mariguana es, ha sido y será, a través del tiempo y de las épocas venideras un estupefaciente del espíritu" (Onetto, 1938, pp. 3 y 4). En su opinión, era urgente desmentir a Leopoldo Salazar, cuya sugerencia de legalizar la "nefasta yerba" la calificaba como "infantil y ridícula", de lo contrario, si se aceptase la posición de Salazar, la sociedad mexicana, "tan susceptible a todos los contagios, tendrá la fisonomía más acentuada del pueblo predispuesto al vasallaje" (Onetto, 1938, pp. 55-56).

En el marco de ese debate, una nota publicada en el diario La Prensa, titulada “¿En qué quedó lo de la marihuana?", aseveraba que los lectores habían quedado en "ayunas de si la marihuana, como el Santo Tribunal de la Inquisición, es una institución difamada, calumniada o efectivamente, algo nefando y odioso" (Podán, 1940, p. 15). En la nota se precisa que la actitud de Salazar Viniegra "extravió momentáneamente a la opinión pública en su caminito llano de que la marihuana es una hierba infernal, tóxica y malsana" (Podán, 1940, p. 15). Ese extravió provocó "revuelo periodístico, y hasta en conatos de polémica, sin que nada, como de costumbre, se sacara en limpio" (Podán, 1940, p. 15). Esta nota retomaba una petición realizada meses atrás por la revista Criminalia: su director, José Ángel Ceniceros, había solicitado a la Academia Nacional de Medicina una explicación clara, pericial y científica sobre las propiedades del cannabis y sobre sus efectos en la sociedad mexicana. Al final, como se analizará en el siguiente punto, la opinión científica y pericial no apareció; no obstante, la criminalización en torno a la planta se endurecería. 


\section{El afianzamiento de la criminalización, 1940-1947}

Ante la incertidumbre científica y jurídica en torno a la marihuana, la revista Criminalia solicitó públicamente a la Academia Nacional de Medicina realizar los estudios necesarios para emitir un "dictamen” sobre esta planta. La nota donde se hace esta petición fue publicada en marzo de 1939 y se tituló "La Academia Nacional de Medicina y el problema de la marihuana”. En ella se puede leer que tras la polémica derivada de las diversas publicaciones confrontadas era necesario que la Academia Nacional de Medicina "defina con mayor análisis qué hay de verdad en esta controversia sobre la toxicidad de la marihuana, cuyo empleo, por desgracia, está tan extendido en nuestras clases populares" (Criminalia, 1939, p. 385). En esta solicitud se precisa que "interesan, principalmente, las terribles consecuencias sociales que acarrea el empleo generalizado de la marihuana" (Criminalia, 1939, p. 385).

Con respecto a esta petición, que no tuvo una respuesta, llama la atención un texto publicado unos cuantos años después, en 1944, titulado "La popular doña juanita. Calumniado y hermoso arbusto", escrito por José Ángel Ceniceros, quien había sido parte de la comisión redactora del Código Penal de 1931 y era el director general de Criminalia. Previo a su publicación en aquella revista, por cierto, el texto "La popular doña juanita" había sido publicado en 1943 dentro del periódico Excélsior. En ambas versiones del texto, sin citar con precisión su fuente, Ceniceros comienza refiriéndose a un artículo de la revista estadounidense Time, donde se afirma que "a pesar de todas las leyendas que se han hecho circular sobre la marihuana, no se han llegado a descubrir casos de degeneración física, mental o moral que puedan atribuirse exclusivamente a ella" (Ceniceros, 1944, p. 326). Apunta que aquel artículo lo llevó a reflexionar lo expuesto por Leopoldo Salazar Viniegra. Reiteró entonces la escasez de evidencia científica sobre el cannabis, y recordó la petición que se le había hecho a la Academia Nacional de Medicina:

Como nos alarmara la afirmación de que la cuestión de la marihuana no merecía la importancia de problema social ni humano, en contraste con el problema del alcoholismo y que se llamara a la planta de la marihuana "calumniado y hermoso arbusto" [haciendo alusión a las afirmaciones realizadas por Leopoldo Salazar], en la revista CRIMINALIA, en la cual publicamos variada literatura sobre ese tema, de distinguidos mexicanos, formulamos respetuosa interpelación a la Academia Nacional de Medicina, a fin de que definiera qué había de verdad en la controversia sobre la toxicidad de la marihuana. (Ceniceros, 1944, p. 328)

En tono de reclamo, Ceniceros concluye su artículo señalando que "No logramos conocer entonces el criterio de tan docta Academia” y, en ese sentido, se preguntaba: “ ¿Nos es permitido ahora, después de haber transcurrido cinco años, durante los cuales sin duda la investigación ha profundizado más, formular nuevamente tan respetuosa interpelación?" (Ceniceros, 1944, p. 328). Ocho décadas han transcurrido desde que la revista Criminalia hiciese aquella petición. El dictamen requerido no fue elaborado por la Academia Nacional de Medicina, y hasta el último lustro - en el que el uso adulto y personal del cannabis fue analizado por la SCJN $(2016,2019)$ y por el Senado de la República $(2020)$, así como su uso medicinal por el Poder Legislativo, por Secretaría de Salud y por el Poder Ejecutivo (2017, 2021)—, ninguna institución pública o privada en México sistematizó la evidencia científica detrás de la farmacología de esta planta. Entre 1944 y la década de 1970 (década en la que aparecen algunas publicaciones sobre la 
marihuana vinculándola con movimientos juveniles) se publicaron en la revista Criminalia unos cuantos artículos aislados relativos al tráfico ilegal de drogas y a las toxicomanías; también decenas de textos sobre el alcoholismo (recordando las preocupaciones propias del Congreso Constituyente, plasmadas en la Constitución de 1917); y varios artículos más que - ajenos a preocupaciones sobre drogas o toxicomanías- mantenían en la agenda y en el diálogo científico las ideas eugenésicas y degeneracionistas. Este vacío relacionado con publicaciones sobre el cannabis no sólo se observa en la revista Criminalia, sino también, como se mencionó previamente, en la revista Eugenesia. De igual forma, como parte de este trabajo de documentación y en vista del vacío historiográfico, se hizo una revisión de la Gaceta Médica de México, tal vez en ella se pudiese encontrar algún pronunciamiento de la Academia Nacional de Medicina. Sin embargo, el hallazgo documental fueron tan solo dos artículos, ambos escritos por Leopoldo Salazar Viniegra: el primero de ellos publicado en 1944, en el cual el autor se mantenía en su línea discursiva, pero en esta ocasión dedicó varias páginas a explicar el vínculo entre el consumo de marihuana y las enfermedades mentales. Este artículo de Salazar Viniegra se tituló "Estado actual de los estudios sobre la marihuana". En él se precisa que aquellos que padecen esquizofrenia suelen usar tóxicos como el cannabis; sin embargo, matiza que a pesar de esa relación no hay evidencia para afirmar que el uso de esta planta cree o provoque esa patología (Salazar, 1944, pp. 385-390). Nada se dice en este texto sobre el dictamen solicitado a la Academia Nacional de Medicina; tampoco nada se menciona sobre el dictamen en el texto posterior, también de Salazar Viniegra, publicado en la misma revista un año después, titulado “Toxicomanías”, en el cual, alejado del tema de la marihuana, el autor criticaba la manera tan decadente en la que el gobierno mexicano trataba a los consumidores de sustancias ilegales (Salazar, 1945, pp. 260-271).

No obstante la ausencia de un dictamen científico sobre la marihuana, para el Estado mexicano esta "droga enervante" seguía siendo considerada un peligro para la salud (de acuerdo con el Código Penal de 1931), y sus consumidores eran tratados como enfermos y delincuentes. En este sentido, sobresale un artículo publicado en 1944 por la revista Criminalia, titulado "Drogas heroicas". Se trata de un texto extenso, escrito recopilando varios "dictámenes", los cuales fueron resultado de lo discutido en las varias sesiones que se llevaron a cabo durante el "Congreso contra el Vicio": un evento organizado por el Departamento del Distrito Federal en coordinación con el Poder Ejecutivo Federal y con varias secretarías. El congreso se realizó en el Palacio de Bellas Artes y tuvo como temas centrales la mirada médico-higiénica, social, laboral, educativa, económica, y jurídica en torno a los diversos vicios. Tras dos semanas de trabajo, prácticamente la totalidad de las mesas se centraron en el alcoholismo, y solamente en las últimas sesiones se habló de "drogas heroicas" y también de prostitución (Criminalia, 1944, p. 320).

El dictamen sobre las "drogas heroicas" expuesto en la revista Criminalia nada menciona sobre la marihuana; sin embargo, presenta una suerte de reflexión sobre la tipificación de los "delitos contra la salud" dentro del Código Penal Federal vigente. Como parte de esa reflexión, se afirmaba que "la solución ideal consistiría en suprimir el vicio y en consecuencia hacer desaparecer el tráfico" (Criminalia, 1944, p. 320). Un tráfico que, es importante subrayarlo, en ese momento era ya un problema social grave y evidente en México (Astorga, 2003). Pero más allá del problema del tráfico ilegal, la comisión que discutió el tema de las drogas prohibidas señalaba que, "derivada de los conocimientos de los factores biológicos y aun fisiológicos de los problemas humanos [se ha identificado a] las toxicomanías como un producto del desequilibrio de las relaciones sociales" (Criminalia, 1944, p. 321). Un desequilibrio social que la 
misma comisión dictaminadora consideraba inevitable. Se percibía y se caracterizaba "al vicioso como un sujeto infradotado socialmente, inconforme con su destino humano y desconectado, por excesos o por defecto, del ritmo veloz que las trasformaciones civilizadoras y culturales imponen a la evolución biológica" (Criminalia, 1944, p. 321). En este dictamen se puede observar cómo, al mediar el siglo XX, las referencias degeneracionistas y eugenésicas se seguían entrecruzando con la protección de la "salud" para crear un híbrido discursivo con el cual justificar la criminalización del uso de ciertas drogas. En este dictamen se proponía un aumento a las penas derivadas de cualquier delito contra la salud en materia de drogas enervantes: se sugerían hasta ocho años de cárcel, que era el doble de la pena contemplada en ese momento por el código vigente, el de 1931; y en este sentido, también se consideraba apropiado incluir en el Código Penal Federal como "delito el hecho de que una persona instigue o induzca a otra al uso de estupefacientes". Las recomendaciones emanadas del "Congreso contra el vicio", celebrado en 1944, serían retomadas tan sólo tres años después, dando lugar a diversas modificaciones al Código Penal en materia de "delitos contra la salud".

Entre septiembre y octubre de 1947 se discutió en la Cámara de Diputados la propuesta de modificación al Código Penal. En esta iniciativa se precisaba que la legislación sobre drogas debía revisarse con urgencia, para así cumplir con las obligaciones internacionales, para evitar la propagación de los vicios y porque "se ha dicho mucho que el uso de las drogas enervantes origina la degeneración de las razas" (Poder Legislativo, 1947a, s/p). Tras esa afirmación, se explica que la "abundantísima experiencia" de aquellos que han trabajado tratando toxicómanos permite "afirmar que efectivamente el uso de las drogas enervantes origina una profunda degradación de los individuos y acarrea una degeneración de la especie" (Poder Legislativo, 1947a, s/p). Con sus argumentos, la lógica legislativa contribuía a afianzar la premisa constitucional que avalaba la relación drogas-degeneración. Se especificaba que era posible percibir esa degeneración de los consumidores de drogas por su enflaquecimiento, anorexia, sequedad de la piel, anemia intensa, fragilidad progresiva, caries dentarias, abscesos en múltiples partes de la piel, canicie precoz " $y$ todas las manifestaciones que un trastorno del sistema neurovegetativo produce" (Poder Legislativo, 1947a, s/p).

La iniciativa fue aprobada y entró en vigor en noviembre de 1947. Esta reforma justificaba su promulgación "al ser nuestro propósito velar celosamente tanto porque en México no se propaguen los vicios que degeneran al individuo, como por el debido cumplimiento de las obligaciones internacionales" (Poder Legislativo Federal, 1947b, s/p). Consecuencia de esta aprobación, destacan varias de las reformas que se hicieron al Código Penal en materia de "delitos contra la salud". Se amplió el catálogo de "drogas enervantes", comprendiendo todas aquellas sustancias dictadas por las convenciones internacionales; aumentó el rigor de las sanciones penales a estos delitos, llegando hasta los diez años de prisión; se estableció que bajo ninguna circunstancia se podría otorgar libertad bajo caución al detenido por "delitos contra la salud"; y se incluyó un nuevo tipo penal: "proselitismo en materia de enervantes", el cual buscaba sancionar a todo aquel que realizara actos de provocación, incitación, inducción, o auxilio para que otra persona consumiera una droga que llevara al individuo a la adquisición de hábitos degeneradores (Poder Ejecutivo Federal, 1947, artículos 193-195).

Cuando en 1947 las reformas al Código Penal Federal endurecieron las penas a los "delitos contra la salud" en general y contra el uso de marihuana en particular, la evidencia científica relacionada con esta planta era insuficiente y su debate era aún escaso. Sin embargo, las autoridades mexicanas seguían 
considerando el uso de cannabis un delito, y en consecuencia avalaban el castigo basándose en la formalidad que brindaba el cumplimiento de un proceso legislativo, aunque éste se basase en criterios no consensuados por los facultativos especialistas en la materia. A falta de consenso y profundidad en el debate médico y jurídico dentro del ámbito nacional, el aval que en términos de evidencia científica pudo brindarle legitimidad a la legislación antimarihuana en México se encontraba en los Tratados Internacionales. Sin embargo, las discusiones detrás de la Convención de Ginebra de 1925, donde se prohibió el cannabis al nivel global —así como las de 1931, 1936, 1948 y las hoy en día vigentes de 1961, 1971 y 1988 - carecieron de debate científico, y la posición anticannabis fue aceptada por las naciones firmantes de manera acrítica (Sociedad de Naciones, 1925; Schievenini, 2018, pp. 391-407; 532-575). De igual forma, las legislaciones que simultáneamente prohibieron la marihuana en otras naciones carecieron de un aval científico sólido y consensuado (Himmelstein, 1983; Carstairs, 2006; Mills, 2013; Dufton, 2017; Schievenini, 2018).

\section{Conclusión}

Los saberes médicos y jurídicos que avalaron las propiedades farmacológicas de ciertos productos — plasmados particularmente en el Código Penal de 1871 y en el Código de Salubridad de 1902- eventualmente idearon bosquejos argumentativos que negaron sus beneficios terapéuticos. En un primer momento prohibieron esos productos - con el decreto de 1920-, después patologizaron a sus usuarios — con el Código Sanitario de 1926 - y finalmente criminalizaron ese uso - con los códigos penales de 1929 y 1931 - . El fundamento legal de cada uno de esos ordenamientos — de 1920, 1926, 1929 y 1931fue la Constitución Política de 1917, particularmente el artículo 73, fracción 16, que en su texto original contempló la "Campaña contra el alcoholismo y la venta de drogas que degeneran la raza". El bien jurídico tutelado detrás de esta preocupación gubernamental fue en un primer momento la "raza", buscando su fortalecimiento. La concepción de esta noción racial no era eugenésica o estrictamente biológica, sino, más bien, social, tendiente a la reconstrucción de una nación tras el caos revolucionario. En un segundo momento - 1929-1931 - el bien jurídico tutelado en la letra de la ley sería la "salud", aunque en las discusiones legislativas y en diversos apartados de la ley se seguía aludiendo a la protección de la raza.

La transición de la protección de la raza a la protección de la salud, evidente en la letra de las leyes en cuestión —1920, 1926, 1929 y 1931 - fue respaldada por una justificación científica imprecisa, lo cual pudo documentarse con la revisión de las revistas Eugenesia, Criminalia y Gaceta Médica de México. De igual forma, la transformación de paradigmas médico-jurídicos en materia de sustancias - transitando de medicamentos a drogas prohibidas- significó que el individuo que usaba legítimamente una droga con fines terapéuticos en los años previos a la prohibición, a partir de la promulgación de las leyes secundarias en materia de drogas - tras la Constitución de 1917- experimentase ya no un beneficio a su salud, sino que, por el contrario, sería señalado por las autoridades - legislativas y judiciales - como sujeto patológico. El individuo consumidor de marihuana, por ejemplo, debía curarse a través de procedimientos profilácticos dada la peligrosidad de su supuesta enfermedad, o debía ser aislado de la sociedad por atentar primero, a partir del decreto de 1920, contra la "raza" y a partir de los códigos penales de 1929 y 1931 por cometer un "delito contra la "salud". Los derechos fundamentales, tanto a la salud como 
a la libertad e incluso al debido proceso - porque se le castigaba sin precisar el daño que se cometía, es decir, sin delimitar con exactitud el bien jurídico afectado—, no fueron una cuestión a considerar dentro del contexto teórico que justificaba estas medidas punitivas. Tras una serie de artículos publicados en las revistas Criminalia y Gaceta Médica de México entre 1939 y 1945, el debate en torno a la marihuana se extraviaría. En los años posteriores, con una discusión científica centrada aún en la degeneración racial, el Código Penal Federal sería modificado. En 1947, endureciendo las penas contra los "delitos contra la salud", la consolidación del paradigma prohibicionista se afianzó en México y se mantendría firme durante el resto del siglo XX y principios del XXI. Esta consolidación se ajustó a la perfección con la pauta dictada por las convenciones internacionales en materia de drogas y por la influencia ejercida por el gobierno de EUA.

El estudio de la relación entre leyes y ciencia en los albores de la prohibición del cannabis en México, realizado en esta investigación, aporta elementos para seguir edificando la emergente Nueva Historia de las Drogas en Latinoamérica. En este sentido, el estudio de casos nacionales análogos y paralelos es una tarea aún pendiente en la historiografía de la región. Asimismo, esta investigación aporta elementos de discusión para el diseño e implementación de la política pública que en materia de cannabis se desarrolla actualmente en México. Se trata de una política pública que tendrá sus bases en el "Reglamento de la Ley General de Salud en materia de control sanitario para la producción, investigación y uso medicinal de la cannabis y sus derivados farmacológicos" (Poder Ejecutivo, 2021) y en la "Ley Federal para la Regulación del Cannabis” (Senado de la República, 2020). Dada la compleja historia del cannabis en México -y en función de los potenciales beneficios y perjuicios que engloban su consumo- el diseño, implementación y revisión de esta nueva política pública requerirá de productos científicos enfocados en la realidad nacional. Conociendo -y habiendo documentado- las imprecisiones científicas y las carencias argumentativas del pasado, sería un descuido mayúsculo repetir los errores legislativos en el futuro.

\section{Referencias}

Aréchiga, E. (2007). Educación, propaganda o 'dictadura sanitaria'. Estrategias discursivas de higiene y salubridad públicas en el México Posrevolucionario, 1917-1945. Estudios de Historia Moderna y Contemporánea de México, 33(033), 57-88.

http://dx.doi.org/10.22201/iih.24485004e.2007.033.3158

Astorga, L. (2003). Drogas sin fronteras. Grijalbo.

Borougerdi, B. (2018). Commodifying Cannabis: A Cultural History of a Complex Plant in the Atlantic World. Lexington Books.

Bouquet, J. (1937). Contributions à l'étude de la Cannabis. Archives de l'Institut Pasteur de Tunis, 29(2), 27-42.

Bouquet, J. (1939). Nuevas contribuciones al estudio de la cannabis. Criminalia, 5(4), 469-478.

Campos, I. (2010). Degeneration and the Origins of Mexico's War on Drugs. Mexican Studies, 26(2), 379-408. https://doi.org/10.1525/msem.2010.26.2.379

Campos, I. (2012). Home Grown, Marijuana and the Origins of Mexico's War on Drugs. The University of North Carolina Press. 
Carstairs, C. (2006). Jailed for Possesion. Ilegal Drug Use, Regulation, and Power in Canada, 1920-1961. University of Toronto Press.

Ceniceros, J. A. (1943, 8 de octubre). La popular doña juanita. Excélsior, 7.

Ceniceros, J. A. (1944). La popular doña juanita. Calumniado y hermoso arbusto. Criminalia, 10(2), 326-328.

Ceniceros, J. A. (1945). La represión del tráfico de drogas enervantes. Criminalia, 11(3), 180-187.

Congreso Constituyente. (2016). Diario de los debates del Congreso Constituyente 1916-1917, tomo III. (Comité para la conmemoración del centenario de la Constitución Política de los Estados Unidos Mexicanos, ed.) Secretaría de Cultura; Instituto Nacional de Estudios Históricos de las Revoluciones en México.

Constitución Política de los Estados Unidos Mexicanos. (1917, 5 de febrero). Diario Oficial, Órgano del gobierno provisional. Tomo $\mathrm{V}$, Cuarta época, número 30. http://www.diputados.gob.mx/LeyesBiblio/ref/cpeum/CPEUM_orig_05feb1917.pdf

Criminalia. (1939). La Academia Nacional de Medicina y el problema de la marihuana. Criminalia, 5(3), 386.

Criminalia. (1944). Drogas heroicas. Criminalia, 10(4), 290-292.

Davenport-Hines, R. (2005). La búsqueda del olvido, historia global de las drogas, 1500-2000. Fondo de Cultura Económica.

Departamento de Estado de los Estados Unidos de América. (1942). Cannabis 1942. [Documento recopilado en la siguiente locación de archivo:] Subject Files Relating to Control of Narcotics Traffic, 1908-1941, fondo 59, caja 11. General Records of the Department of State. National Archives at College Park, Maryland.

Departamento del Tesoro de los Estados Unidos de América. (1916, 10 de enero). U.S. Treasury Department to Mexican Secretary of State. [Documento recopilado en la siguiente locación de archivo:] Dirección General de Consulados y Embajada de México en Estados Unidos, expediente 501/1017. Archivo Genaro Estrada de la Secretaría de Relaciones Exteriores, Ciudad de México.

Departamento de Salubridad Pública. (1926). Código Sanitario de los Estados Unidos Mexicanos. Imprenta de Manuel León Sánches.

Dufton, E. (2017). Grass Roots: The Rise and Fall and Rise of Marijuana in America. Basic Books.

El Nacional. (1939, 3 de agosto). La marihuana, 9.

El Universal. (1939, 14 de marzo). Estudio sobre la marihuana, 17.

Elizarras, F. (1939, 8 de febrero). Marihuana. El Nacional, 14.

Esquivel, R. y González, M. (1939). Marihuana. Criminalia, 5(2), 370-377.

González, M. (1988). Las ideas raciales de los científicos, 1890-1910. Historia Mexicana, 37(4), 565-583.

Gootenberg, P. y Campos, I. (2015). Toward a New Drug History of Latin America: A Research Frontier at the Center of Debates. Hispanic American Historical Review, 95(1), 1-35. https://doi. org/10.1215/00182168-2836796

Guba, D. (2020). Taming Cannabis, Volume 1: Drugs and Empire in Nineteenth-Century France. McGillQueen's University Press.

Himmelstein, J. (1983). The Strange Career of Marihuana: Politics and Ideology of Drug Control in America (Contributions in Political Science). Greenwood Press. 
Knight, A. (1990). Racism, Revolution, and Indigenismo: Mexico, 1910-1940. En R. Graham (ed.), The Idea of Race in Latin America, 1870-1940 (Critical Reflections on Latin America Series) (pp. 71-114). University of Texas Press.

La Prensa. (1939, 9 de marzo). Opinión de los lectores, 20.

Mills, J. (2013). Cannabis Nation: Control and Consumption in Britain, 1928-2008. Oxford University Press.

Ministerio de Justicia e Instrucción Pública y Congreso de la Unión. (1871). Código Penal para el Distrito Federal y territorio de la Baja-California sobre delitos del fuero común y para toda la Republica sobre delitos contra la Federación. Editorial Oficial.

Onetto, G. (1931). La mariguana ante la psiquiatría y el Código Penal. Congreso de la Asociación Médica Panamericana.

Onetto, G. (1938). La mariguana ante la Academia Nacional de Medicina. Refutación al trabajo presentado por el doctor Leopoldo Salazar y Viniegra. S/E. Pérez, C. (2016, marzo). Procesamiento de los delitos contra la salud en México [Ponencia] Senado de la República. http://www.senado.gob.mx/comisiones/relext_orgint/ungass/docs/presentaciones/Catalina-Perez-Correa-senado-UNGASS.pdf

Pérez, R. (2016). Tolerancia y prohibición. Aproximaciones a la historia social y cultural de las drogas en México, 1840-1940. Penguin Random House Grupo Editorial.

Piccato, P. (1992). El discurso sobre el alcoholismo en el Congreso Constituyente de 1916-1917. Instituto de Investigaciones Legislativas; Instituto Nacional de Estudios Históricos de las Revoluciones en México.

Podán, M. (1940, 18 de enero). ¿En qué quedó lo de la marihuana? La prensa, 15.

Poder Ejecutivo Federal de los Estados Unidos Mexicanos y Secretaría de Gobernación. (1903). Código Sanitario de los Estados Unidos Mexicanos. Herrero Hermanos Editores.

Poder Ejecutivo Federal de los Estados Unidos Mexicanos y Secretaría de Gobernación. (1920, 15 de marzo). Disposiciones sobre el comercio de productos que pueden ser utilizados para fomentar vicios que degeneren la raza y sobre el cultivo de plantas que pueden ser empleadas con el mismo fin. Diario Oficial, $X I V(63)$.

Poder Ejecutivo Federal de los Estados Unidos Mexicanos y Secretaría de Gobernación. (1929). Código Penal para el Distrito y Territorio Federales en materia de fuero común y para toda la República en materia del fuero federal. Escuela Lino-topográfica Salesiana.

Poder Ejecutivo Federal de los Estados Unidos Mexicanos y Secretaría de Gobernación. (1931). Código Penal para el Distrito y Territorio Federales en materia de fuero común y para toda la República en materia del fuero federal. Talleres Gráficos de la Nación.

Poder Ejecutivo Federal de los Estados Unidos Mexicanos. (1931b, 27 de octubre). Reglamento Federal de Toxicomanía. Diario Oficial de la Federación, LXVIII(46).

Poder Ejecutivo Federal de los Estados Unidos Mexicanos. (1947, 14 de noviembre). Decreto que reforma y adiciona los artículos 193, 194 y 197 del Código Penal para el Distrito Federal y Territorios Federales en materia de Fuero Común y para toda la República en materia de Fuero Federal. Diario Oficial de la Federación, $C L X V(12)$.

Poder Ejecutivo Federal de los Estados Unidos Mexicanos y Secretaría de Salud. (2017, 19 de junio). Decreto por el que se reforman y adicionan diversas disposiciones de la Ley General de Salud y del Código Penal Federal. Diario Oficial de la Federación, DCCLXV(14). 
Poder Ejecutivo Federal de los Estados Unidos Mexicanos. (2021, 12 de enero). Reglamento de la Ley General de Salud en materia de control sanitario para la producción, investigación y uso medicinal de la cannabis y sus derivados farmacológicos. Diario Oficial de la Federación. https://www.dof.gob. $\mathrm{mx} /$ nota_detalle.php?codigo $=5609709 \&$ fecha $=12 / 01 / 2021$

Poder Legislativo de los Estados Unidos Mexicanos. (1947, 29 de septiembre). Diario de los Debates de la Cámara de Diputados del Congreso de los Estados Unidos Mexicanos. Tomo I, Año II, Número 10, XL Legislatura. http://cronica.diputados.gob.mx /DDebates/40/2do/Ord/19471007.html

Poder Legislativo Federal de los Estados Unidos Mexicanos. (1947b, 7 de octubre). Diario de los Debates de la Cámara de Diputados del Congreso de los Estados Unidos Mexicanos. Tomo II, Año II, Número 11, XL Legislatura.

http://cronica.diputados.gob.mx/DDebates/40/2do/Ord/19470930.html

Rojas, O. (2016). La ciudad y sus peligros: alcohol, crimen y bajos fondos. Visiones, discursos y práctica judicial, 1929-1946 [tesis de doctorado, Universidad Nacional Autónoma de México]. Repositorio de la Dirección General de Bibliotecas y Servicios Digitales de Información UNAM. https://repositorio. unam.mx/contenidos/68836

Ruiz, R. (1987). Positivismo y evolución: introducción del darwinismo en México. Universidad Nacional Autónoma de México.

Saavedra, A. (1940). Los narcómanos. Eugenesia. Higiene y cultura física. Órgano de la Sociedad Eugénica Mexicana, 16(1), 22-23.

Salazar, L. (1939). El mito de la Marihuana. Criminalia, 6(4), 206-237.

Salazar, L. (1944). Estado actual de los estudios sobre la marihuana. Gaceta Médica de México, 19(4), 383-396.

Salazar, L. (1945). Toxicomanías. Gaceta Médica de México, 20(6), 260-271.

Schievenini, J. D. (2018). La criminalización del consumo de marihuana en México, 1912-1961 [tesis de doctorado, Universidad Nacional Autónoma de México]. Repositorio de la Dirección General de Bibliotecas y Servicios Digitales de Información UNAM. https://repositorio.unam.mx/conteni$\operatorname{dos} / 87263$

Schievenini, J. D. (2021). A Historical Approach to the Criminalization of Marijuana Use in Mexico. En L. Richert y J. Mills (eds.), Cannabis. Global Histories (pp. 131-156). The MIT Press.

Segura, J. (1939). La marihuana. Estudio médico y social. Editorial Cultura.

Senado de la República de los Estados Unidos Mexicanos. (2020, 19 de noviembre). Dictamen de las Comisiones Unidas de Justicia, Salud y Estudios Legislativos, Segunda, con opinión de la Comisión de Seguridad Pública, por el que se expide la Ley Federal para la Regulación del Cannabis, y se reforman y adicionan diversas disposiciones de la Ley General de Salud y del Código Penal Federal. Gaceta del Senado de la República. https://www.senado.gob.mx/64/gaceta_del_senado/documento/114017?f bclid=IwAR1kZOFm9_iaObsxKcYTb-3MdKshEbGpdaNoTbWqmu36_iNHP0YUXsRhBpo

Smith, B. (2019). The Dialectics of Dope: Leopoldo Salazar Viniegra, the Myth of Marijuana, and Mexico's State Drug Monopoly. En S. Wilson (ed.), Prohibitions and Psychoactive Substances in History, Culture and Theory: Prohibitions and Psychoactive Substances (pp. 106-128). Taylor \& Francis.

Sociedad Eugénica Mexicana. (1932). Decálogo Eugénico. Sociedad Eugénica Mexicana "Para el mejoramiento de la raza", 5(1), 20. 
Sociedad Eugénica Mexicana. (1932b). El alcoholismo. Sociedad Eugénica Mexicana "Para el mejoramiento de la raza", 5(2), 17.

Sociedad Eugénica Mexicana. (1932c). Congreso Nacional Penitenciario. Eugenesia. Higiene y cultura física. Órgano de la Sociedad Eugénica Mexicana, 5(4), 39.

Sociedad Eugénica Mexicana. (1950). Editorial. Eugenesia. Higiene y cultura física. Órgano de la Sociedad Eugénica Mexicana, 28(3), 47.

Sociedad de Naciones. (1925). Records of the Second Opium Conference, Geneva \& Plenary Meetings Text of the Debates. [Documento recopilado en la siguiente locación de archivo:] League of Nations 1919-1947, Assembly Council Circular Letters, microfilm I-C760.M260, carrete 5. British Library, Londres.

Sociedad de Naciones. (1936). Geneva Convention. [Documento recopilado en la siguiente locación de archivo:] Subject of the Bureau of Narcotics and Dangerous Drugs, 1917-1970, fondo 170, caja 13. Records of Drug Enforcement Administration. National Archives at College Park, Maryland.

Suprema Corte de Justicia de la Nación. (2016, 25 de Noviembre). Derecho al libre desarrollo de la personalidad. La prohibición para el autoconsumo de marihuana contenida en la Ley General de Salud incide prima facie en el contenido de dicho derecho fundamental. Tesis aislada. Decima Época, Primera Sala. Semanario Judicial de la Federación.

Suprema Corte de Justicia de la Nación. (2019, 22 de Febrero). Inconstitucionalidad de la prohibición absoluta al consumo lúdico o recreativo de marihuana prevista por la ley general de salud. Jurisprudencia Constitucional. Decima Época, Primera Sala. Semanario Judicial de la Federación.

Speckman, E. (2008). Reforma legal y opinión pública: los códigos penales de 1871, 1929 y 1931. En A. Alvarado (ed.), La reforma de la justicia en México (pp. 575-614). El Colegio de México.

Stepan, N. (1991). The Hour of Eugenics. Race, Gender, and Nation in Latin America. Cornell University Press.

Suárez, L. (2006). Eugenesia y Racismo en México. Universidad Nacional Autónoma de México.

Urías, B. (2005). Locura y criminalidad: degeneracionismo e higiene mental en México posrevolucionario 1920-1940. En E. Speckman y C. Agostoni (eds.), De normas y transgresiones. Enfermedad y crimen en América Latina (1850-1950) (pp. 347-383). Universidad Nacional Autónoma de México.

Urquijo, A. (1939, 1 de marzo). La mariguana sí es tóxica. El Universal, 3.

Yawger, N. S. (1938). Marijuana. Our New Addiction. American Journal of the Medical Sciences, 19(5), 351-357.

Yawger, N. S. (1939). Marihuana, el nuevo vicio. Criminalia, 6(1), 269-272. 